\title{
The effect of conditioned inhibitors and preexposed cues on the outcome-specific Pavlovian-to-instrumental transfer (PIT) effect in humans
}

\begin{tabular}{|c|c|}
\hline Journal: & Quarterly Journal of Experimental Psychology \\
\hline Manuscript ID & QJE-STD-19-100.R2 \\
\hline Manuscript Type: & Standard Article \\
\hline $\begin{array}{r}\text { Date Submitted by the } \\
\text { Author: }\end{array}$ & $15-O c t-2019$ \\
\hline Complete List of Authors: & $\begin{array}{l}\text { Alarcon, Daniel; University of Chile, Psychology } \\
\text { Bonardi, Charlotte; University of Nottingham, Psychology }\end{array}$ \\
\hline Keywords: & $\begin{array}{l}\text { Pavlovian-to-instrumental transfer (PIT), conditioned inhibition, decision } \\
\text { making, cue-reactivity, goal directed }\end{array}$ \\
\hline
\end{tabular}

\section{SCHOLARONE \\ Manuscripts}




\title{
The effect of conditioned inhibitors and preexposed
}

\section{cues on the outcome-specific Pavlovian-to-instrumental transfer (PIT) effect in humans}

\author{
Daniel E. Alarcón ${ }^{1,2}$ \& Charlotte Bonardi ${ }^{2}$ \\ ${ }^{1}$ Departamento de Psicología, Universidad de Chile, Chile \\ 2 School of Psychology, University of Nottingham, UK
}

Corresponding Author:

Daniel E. Alarcón

Av. Capitán Ignacio Carrera Pinto N¹045

Santiago, Chile

Phone: +56 229787784

E-mail: dealarcon@u.uchile.cl 
Using a human Pavlovian-to-instrumental transfer (PIT) task Alarcón and Bonardi (2016) showed that the selective elevation of instrumental responding produced by excitatory transfer cues was reduced when these cues were presented with a conditioned inhibitor $(\mathrm{Cl})$, relative to a control cue that was simply preexposed. However, previous research has shown that preexposed cues might also acquire inhibitor-like properties. The present study aimed to contrast the inhibitory properties of Cls and preexposed cues, using novel stimuli as controls, in summation and PIT tests. Participants were trained to perform two actions, each reinforced with a distinct outcome $\left(\mathrm{O}_{1}\right.$ or $\left.\mathrm{O}_{2}\right)$. Two images were trained as Cls, each signalling the absence of one of the outcomes, by presenting them with a cue that was otherwise followed by that outcome (e.g., $A \rightarrow O_{1}, A I \rightarrow$ no $O_{1}$ ). In contrast, the preexposed cues were simply presented in the absence of the outcomes. In the summation test participants rated the likelihood of the outcomes in the presence of two independently trained excitatory cues, each presented with either a $\mathrm{Cl}$, a preexposed cue, or a novel stimulus. Similarly, in the PIT test participants performed both actions in the presence and absence of these compounds. In the summation test the Cls and the preexposed cues reduced participants' expectations of the outcomes more than the novel stimuli. However, in the PIT test only the Cls reduced the selective elevation of responding produced by the transfer cues. These results might reflect distinct properties of stimuli trained as Cls and those simply preexposed.

Keywords: Pavlovian-to-instrumental transfer (PIT); conditioned inhibition; decision making; incentive motivation; cue-reactivity 
A conditioned inhibitor $(\mathrm{Cl})$ signals the absence of a significant event. For example, if a conditioned stimulus (CS) A is always paired with an unconditioned stimulus (US)

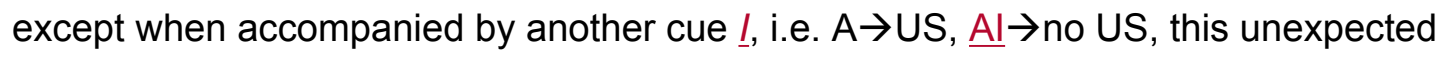
omission of the US drives $-\underline{I}$ to acquire inhibitory properties opposite to those of A. These are often evaluated in summation or retardation tests (Rescorla, 1969). In the summation test the $\mathrm{Cl}$ is presented in compound with a separately trained signal for the US. Inhibition is evident if the $\mathrm{Cl}$ suppresses this cue's ability to predict the US more than a control stimulus. In the retardation test the inhibitor and a suitable control stimulus are both separately paired with a new US and the rate of acquisition is compared; learning an excitatory relationship should be slower if the stimulus is an inhibitor.

Alarcón and Bonardi (2016) recently demonstrated conditioned inhibition in a different manner, using a human Pavlovian-to-instrumental transfer (PIT) task (for reviews on PIT see Holmes, Marchand, \& Coutureau, 2010; Cartoni, Balleine, \& Baldassarre, 2016). Participants were trained to perform two responses $\left(R_{1}, R_{2}\right)$, each reinforced by a distinct outcome (pictures of food or drinks $\mathrm{O}_{1}, \mathrm{O}_{2}$; i.e. $\mathrm{R}_{1} \rightarrow \mathrm{O}_{1} ; \mathrm{R}_{2} \rightarrow \mathrm{O}_{2}$ ). Two neutral images that were later used as transfer cues, $\mathrm{T}_{1}$ and $\mathrm{T}_{2}$, were paired with the same outcomes (i.e. $\mathrm{T}_{1} \rightarrow \mathrm{O}_{1} ; \mathrm{T}_{2} \rightarrow \mathrm{O}_{2}$ ), and in a subsequent PIT test participants performed $\mathrm{R}_{1}$ and $R_{2}$ while $T_{1}$ and $T_{2}$ were presented with one of two neutral control stimuli, $C_{1}$ and $C_{2}$ $\left(T_{1} C_{1} / T_{2} C_{2}\right)$. Participants performed $R_{1}$ more than $R_{2}$ during $T_{1} C_{1}$, but the reverse during $\mathrm{T}_{2} \mathrm{C}_{2}$ - a selective elevation of instrumental responding known as outcome-specific PIT. It has been argued that PIT results from the associations between both $R_{1}$ and $T_{1}$ with $O_{1}$ : presentation of $T_{1}$ activates the $O_{1}$ representation, which elicits performance of $R_{1}$ _cf. Trapold \& Overmier, 1972). This contrasts with the general form of PIT, in which a CS invigorates instrumental responding regardless of whether the CS and the instrumental 


\section{responses are trained with the same or different outcomes, as long as they are both of the} same motivational valence (cf. Rescorla \& Solomon, 1967).

In addition, Alarcón and Bonardi (2016) paired a stimulus $\mathrm{S}_{1}$ with $\mathrm{O}_{1}$ unless accompanied by an inhibitor $I_{1}\left(S_{1} \rightarrow O_{1} ; S_{1} l_{1} \rightarrow\right.$ no $\left.O\right)$, making $I_{1}$ an inhibitor for $O_{1}$. In the PIT test the selective elevation of responding during $T_{1} C_{1}$ and $T_{2} C_{2}$ was eliminated when $T_{1}$ and $T_{2}$ were presented with inhibitor $I_{1}\left(T_{1} l_{1} / T_{2} l_{1}\right)$. Pavlovian inhibitors are commonly thought to act by suppressing activation of the outcome representation, and so the authors attributed this effect to $\mathrm{I}_{1}$ 's inhibitory properties interfering with the $T_{1} \rightarrow \mathrm{O}_{1} \rightarrow \mathrm{R}_{1}$ chain that mediates PIT. This conclusion was supported by the results of a summation test (cf. Rescorla, 1969), in which participants' expectation of $\mathrm{O}_{1}$ and $\mathrm{O}_{2}$ during $\mathrm{T}_{1}$ and $\mathrm{T}_{2}$ respectively was significantly weaker during $T_{1} l_{1}$ and $T_{2} l_{1}$ than during $T_{1} C_{1}$ and $T_{2} C_{2}$.

In that study the control stimuli $\mathrm{C}_{1}$ and $\mathrm{C}_{2}$ were preexposed in compound in the absence of any outcome, meaning they were treated identically to $\perp$ except for never being presented with an excitatory CS - so they should not have become inhibitory. However, some have argued that, because the context in which the cue is presented also elicits expectancy of the US, this is sufficient for the stimulus to develop what is termed differential inhibition (see Miller, Hallam, Hong, \& Dufore, 1991). For instance, Karazinov and Boakes (2004) reported that a $\mathrm{Cl}$ and a preexposed stimulus both reduced expectation of the US relative to a novel cue - although the $\mathrm{CI}$ did this more effectively than the preexposed cue. However, in further experiments the authors tried to enhance the "inhibitory" properties of the preexposed cue by increasing the excitatory strength of the context during training. Despite these manipulations, the degree to which the preexposed cues reduced participants' expectations of the US did not change - not what would be expected if differential inhibition were responsible. Nonetheless, these findings raise the 
possibility that the control cues in our PIT study might also appear inhibitory relative to a novel control stimulus. The present study explored this possibility.

Alarcón and Bonardi (2016) also found that the effect of the Cl was not outcomespecific: although $\_$only signalled the absence of $\mathrm{O}_{1}$, in the summation test it reduced expectation of $\mathrm{O}_{2}$ during $T_{2}$ as effectively as expectation of $\mathrm{O}_{1}$ during $T_{1}$, and also suppressed the PIT effect produced by $T_{1}$ and $T_{2}$ to a similar extent. This suggests ! predicted the absence of both outcomes, even though it had only been trained as a signal for omission of $\mathrm{O}_{1}$. Although some previous studies have reported evidence consistent with these results (e.g., LoLordo, 1967; Nieto, 1984; Pearce, Montgomery \& Dickinson, 1981), there are also several studies showing that an inhibitor is more effective in reducing responses to a cue that signals the same outcome as that inhibited by the inhibitor (e.g.) Delamater, Sosa, \& LoLordo, 2003). Although the factors determining whether the inhibitors will act in a general or an outcome-specific manner is unclear, in the case of Alarcón and Bonardi (2016) it may have been because only one inhibitor was trained; perhaps if an inhibitor had also been trained for $\mathrm{O}_{2}$, the inhibitors would act more selectively. This possibility was also explored.

\section{In the present study we used an outcome-specific PIT design to assess the effect} of two inhibitors, each signalling the absence of a distinct outcome, in summation and PIT tests. Initially participants received instrumental training in which $\mathrm{R}_{1}$ and $\mathrm{R}_{2}$ produced outcomes $\mathrm{O}_{1}$ and $\mathrm{O}_{2}$ (Table 1). After this they were trained that images $\mathrm{S}_{1}$ and $\mathrm{S}_{2}$ (in compound with filler cues $A$ and $B$ ) produced $\mathrm{O}_{1}$ and $\mathrm{O}_{2}$ unless accompanied by $\mathrm{I}_{1}$ and $\mathrm{I}_{2}$; thus $I_{1}$ and $I_{2}$ predicted the absence of $O_{1}$ and $O_{2}$ respectively $\left(S_{1} A \rightarrow O_{1} S_{1} I_{1}-S_{2} B \rightarrow O_{2} S_{2}\right.$ $\underline{\mathrm{l}_{2}-}$ ). Two transfer stimuli, $\mathrm{T}_{1}$ and $\mathrm{T}_{2}$ were also paired with $\mathrm{O}_{1}$ and $\mathrm{O}_{2}$, and the critical control cues $\mathrm{C}_{1}$ and $\mathrm{C}_{2}$ were presented in compound without reinforcement, the same number of times as $I_{1}$ and $I_{2} ; I_{1}, I_{2}, C_{1}$ and $C_{2}$ were also presented in isolation. 
$\underline{\text { In the subsequent summation test we measured participants' expectations of the }}$ outcomes by presenting CSs signalling those outcomes together with the inhibitors or with

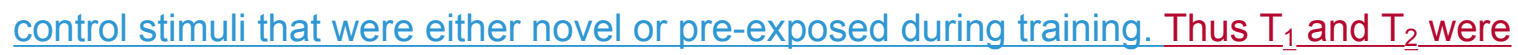
presented with the inhibitors for the outcomes they predicted ( $\mathrm{T}_{1} \underline{1}_{1}$ and $\mathrm{T}_{2} \underline{1}_{2}$ respectively). the preexposed cues $\mathrm{C}_{1}$ and $\mathrm{C}_{2}\left(\mathrm{~T}_{1} \underline{\mathrm{C}}_{1}\right.$ and $\left.\mathrm{T}_{2} \underline{\mathrm{C}_{2}}\right)$ and two novel cues $\mathrm{N}_{1}$ and $\mathrm{N}_{2} \underline{\mathrm{T}_{1}} \underline{\mathrm{N}}_{1}$ and $\underline{\mathrm{T}_{2}} \mathrm{~N}_{2}$ ). This novel control condition allowed us to evaluate the extent to which the preexposed cues $\mathrm{C}_{1}$ and $\mathrm{C}_{2}$ had become differential inhibitors, and acquired inhibitory properties similar to those shown by $\mathrm{I}_{1}$ and $\mathrm{I}_{2}$. We expected a greater reduction of participants' expectations to be produced by the inhibitors than the novel control cue; the question was whether the preexposed control cue would also demonstrate inhibitory properties, reducing expectation of the outcome more than the novel stimulus. In addition, $\underline{T}_{1}$ and $T_{2}$ were also presented with inhibitors for the alternative outcomes $\left(T_{1} \underline{I}_{2}\right.$ and $\left.T_{2} \underline{I}_{1}\right)$, to establish whether training inhibitors for both outcomes would render them outcomespecific. If inhibition is outcome-specific, lower expectation of the outcomes should be evident when the CS and the inhibitor were both trained with the same outcome.

In the PIT test which followed we compared the effect of the inhibitors and preexposed control cues on outcome-specific PIT, by presenting the CSs in compound with either the conditioned inhibitors, the preexposed stimuli or the novel control cues $\left(\mathrm{T}_{1} \underline{1}_{1}\right.$

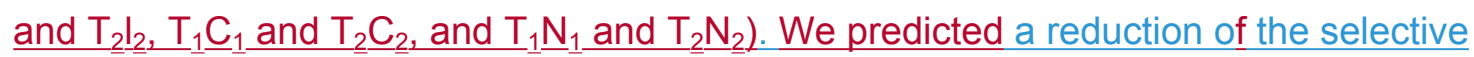
elevation of instrumental performance produced by the CSs, i.e., outcome-specific PIT, when these cues were presented with the inhibitors relative to the novel control cues; the question was again whether the preexposed control cues also displayed inhibitory properties, reducing outcome-specific PIT more than the novel stimuli.

\section{[Table 1 here]}

\section{Method}




\section{Participants}

The participants were 27 students from the University of Nottingham, aged 18-28 (4 males, 23 females). One participant was excluded for only performing one of the two responses in the instrumental phase. Students from the School of Psychology received course credit and the rest received an inconvenience allowance of $£ 4$. The number of participants was chosen based on the number of counterbalancing conditions and on previous studies conducted by the authors (Alarcón \& Bonardi, 2016).

\section{Apparatus and materials}

The task was programmed in PsychoPy (Peirce, 2007) on a standard computer with a 20-inch screen. Twelve neutral fractal images were used as CSs, and images of foods and drinks (4 of each) as outcomes. All images were $8 \times 8 \mathrm{~cm}$ (see Alarcón, Bonardi \& Delamater, 2018). The neutral images were presented immediately to the left or right of the screen centre, and the outcomes were presented centrally. The components of each neutral stimulus compound were presented an equal number of times on the left and right. A fixation cross $(10 \times 10 \mathrm{~mm})$ was located at the centre of the screen in the instrumental phase and PIT test, and was replaced by a fixation dot $(3 \times 3 \mathrm{~mm})$ in the Pavlovian phase. $R_{1}$ and $R_{2}$ were pressing the keys ' $z$ ' and ' $m$ '. For half of the participants ' $z$ ' was reinforced with food and ' $m$ ' with drink, and the reverse for the remaining participants. In the summation test participants used the mouse to click on the rating scale, and the 'space' bar to advance through the phases. Instructions were presented on the screen before each phase.

\section{Procedure}

Participants received a brief explanation of the task, and then completed a consent form before they were guided into a quiet room. 


\section{Instrumental training}

Participants were instructed to learn the relationships between pressing the ' $z$ ' and 'm' keys and different rewards (images of foods or drinks), and to obtain as many rewards as they could. Each response was reinforced according to a variable ratio (VR) 5 schedule, such that an outcome was presented after an average of five responses. Each outcome was presented in the centre of the screen, either until $0.8 \mathrm{~s}$ had elapsed or until another key was pressed, at which point it was replaced by the fixation cross. This phase ended when participants had received 100 outcomes in total.

\section{Pavlovian phase}

Participants were informed that different images would appear on the screen, some of them followed by the rewards and others not, and that they would have to answer a series of questions about these relationships by pressing numbers on the keyboard. In each trial, the text "Which reward will appear now?" was presented at the top of the screen, one CS image (or compound) below it, and the text "1) Food 5) Drink 9) Nothing" at the bottom. When participants pressed one of the numbers on the keyboard (1, 5 or 9$)$, these stimuli were removed from the screen and the correct outcome was presented; in addition, depending on the participant's response, the text "Correct!" in green font, or "Oops! That was wrong" in red font, was presented at the top or bottom of the screen, respectively. The intertrial interval (ITI) was $2 \mathrm{~s}$, in which only the fixation dot was present.

The initial, pre-training stage was divided into two blocks, each comprising 4 trials of $S_{1} \rightarrow O_{1}$ and 4 of $S_{2} \rightarrow O_{2}$, to establish $S_{1}$ and $S_{2}$ as signals for their respective outcomes. The inhibitory stage that followed was divided into two blocks, each comprising 4 trials of $S_{1} A \rightarrow O_{1}$ and $S_{2} B \rightarrow O_{2}, 6$ trials each of $T_{1} \rightarrow O_{1}, T_{2} \rightarrow O_{2}, S_{1} I_{1^{-}}, S_{2} I_{2^{-}}$and $C_{1} C_{2^{-}}$, and 3 trials of $\mathrm{I}_{1^{-}}, \mathrm{I}_{2^{-}}, \mathrm{C}_{1}$ and $\mathrm{C}_{2}$ (Table 1 ). The filler cues $\mathrm{A}$ and $\mathrm{B}$ were added to $\mathrm{S}_{1}$ and $\mathrm{S}_{2}$ on 
reinforced trials to ensure that participants could not simply learn that when two cues were presented no outcome followed, without needing to pay attention to the individual cues in each compound. The order of the trial types was semi-random within each block. Participants could, if they wished, take a break between these blocks.

\section{Summation test}

Participants were informed that images would appear on the screen, after which they must rate the likelihood of an outcome's appearance using a rating scale. On each trial the text "In a scale from 1 to 100 , how likely is it that this image will be followed by" together with the word "FOOD" or "DRINK" was presented at the top of the screen. For half of the trials the questions ended with the word "FOOD" and the compounds consisted of the transfer cue signalling food with either the inhibitor trained with food, e.g., $\mathrm{T}_{1} \underline{1}_{1}$, the

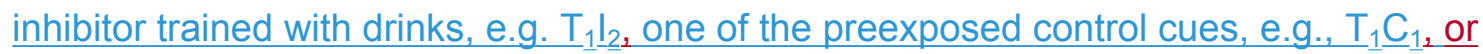
one of the novel cues, $\mathrm{T}_{1} \underline{N}_{1}$. For the other half the question ended with the word "DRINK", and the stimuli presented were corresponding compounds containing the transfer cue signalling drink, e.g., $\underline{T}_{2} \underline{I}_{2}, T_{2} \underline{1}_{1}, T_{2} \underline{C}_{2}$, and $\underline{T}_{2} \underline{N}_{2}-\underline{N}_{-}$The compounds were presented, and below them a rating scale with ' 0 ' on the left and '100' on the right. The test consisted of two blocks, each comprising two trials of each compound (Table 1); the order of questions was randomized within each block.

\section{Instrumental retraining}

This was designed to serve as a reminder of the specific R-O associations learned at the beginning of the experiment, and was identical to the initial instrumental phase, except participants earned only 50 outcomes in total.

\section{PIT test}


Participants were instructed to press either ' $z$ ' or ' $m$ ' as much as they wanted in order to obtain the rewards, but no outcomes were presented. In each trial the fixation dot was present for $2 \mathrm{~s}$ (pre-CS baseline period), followed by a 2-s CS presentation (CS period). The test was divided into three blocks, each comprising 2 presentations of each stimulus compound, presented in a semi-random order.

\section{Data treatment}

The data were analysed using analysis of variance (ANOVA). Significant two-way interactions were explored with simple main effects analysis using the pooled error term. Partial eta-squared $\left(\eta_{p}{ }^{2}\right)$ and its $90 \%$ confidence interval were given for significant effects and interactions. The responses made in the Pavlovian conditioning trials were grouped as "correct" if participants chose the outcome predicted by the cues to the question "Which reward will appear now?", and "incorrect" if they chose either the other outcome or the "nothing" option (see below). Responses in the PIT test were computed separately for CS and preCS periods, transformed to responses per minute (rpm) and grouped according to the outcome signalled by the transfer cue and the response. Responses trained with the same outcome as that signalled by the transfer cue were grouped as Same, e.g., $R_{1}$ during $T_{1}$ compounds, otherwise as Different, e.g. $R_{2}$ during $T_{1}$ compounds. Difference scores were calculated by subtracting responding during the pre-CS period from that during the CS period. Positive scores reflect an elevation of responding over background levels, and higher Same than Different scores reflect outcome-specific PIT.

\section{Results}

The Pavlovian and instrumental phases were completed uneventfully. The mean number of $R_{1}$ responses and $O_{1}$ presentations were $269.9(\mathrm{SEM}=14.4)$ and $51.8(\mathrm{SEM}=$ 2.9), respectively, and for $R_{2}$ and $\mathrm{O}_{2} 251.2(\mathrm{SEM}=13.4)$ and $54.4(\mathrm{SEM}=2.9)$, 
respectively. The mean proportion of correct responses in the inhibitory training $(0=$ no correct answers, 1 = all correct answers), for blocks 1 and 2 respectively, were 0.58-0.58 $(\mathrm{SEM}=0.05-0.06)$ for $\mathrm{S}_{1} \mathrm{~A} / \mathrm{S}_{2} \mathrm{~B} ; 0.55-0.76(\mathrm{SEM}=0.04-0.05)$ for $\mathrm{S}_{1} \mathrm{I}_{1} / \mathrm{S}_{2} \mathrm{I}_{2} ; 0.82-0.92(\mathrm{SEM}$ $=0.05-0.04)$ for $C_{1} C_{2} ; 0.63-0.87(S E M=0.03-0.03)$ for $T_{1} / T_{2} ; 0.69-0.87(S E M=0.05-0.05)$ for $I_{1} / I_{2}$; and 0.65-0.9 (SEM = 0.05-0.05) for $C_{1} / C_{2}$. An ANOVA with Block $(1,2)$ and Cue $\left(S_{1} A / S_{2} B, S_{1} l_{1} / S_{2} I_{2}, C_{1} C_{2}, T_{1} / T_{2}, I_{1} / I_{2}, C_{1} / C_{2}\right)$ showed a significant main effect of Block, $F(1$, $25)=61.18, M S e=.03, p<.001$, significant main effect of Cue, $F(5,125)=10.06, M S e=$ $.05, p<.001$, and a significant Block $x$ Cue interaction, $F(5,125)=4.73, M S e=.024, p=$ .001 . The analysis of the interaction confirmed more correct responses in block 2 relative to block 1 for compounds $S_{1} l_{1} / S_{2} I_{2}(p<.001), C_{1} C_{2}(p=.001), T_{1} / T_{2}(p<.001), I_{1} / I_{2}(p<$ $.001), C_{1} / C_{2}(p<.001)$, but not for $S_{1} A / S_{2} B(p=.86)$. In view of the fact that performance on $S_{1} A / S_{2} B$ trials did not increase over blocks, we further explored the incorrect responses to these compounds, and found that in $83 \%$ of the cases participants chose the option "nothing" (rather than the alternative outcome). This was likely caused by $\mathrm{S}_{1}$ and $\mathrm{S}_{2} \underline{\text { also }}$

\section{being paired with the absence of the outcomes when presented with the inhibitors,} rendering them potentially ambiguous cues.

The rating scores in the summation test to $T_{1}$ and $T_{2}$, according to whether they were paired with the corresponding $\mathrm{Cl}\left(\mathrm{T}_{1} \mathrm{l}_{1}\right.$ and $\left.\mathrm{T}_{2} \mathrm{l}_{2}\right)$, the preexposed control cue $\left(\mathrm{T}_{1} \mathrm{C}_{1}\right.$ and $\left.T_{2} C_{2}\right)$, the novel control cue $\left(T_{1} N_{1}\right.$ and $\left.T_{2} N_{2}\right)$ or the alternative inhibitor $\left(T_{1} l_{2}\right.$ and $\left.T_{2} l_{1}\right)$, are plotted in Figure 1. An ANOVA with Outcome $\left(\mathrm{O}_{1}, \mathrm{O}_{2}\right)$ and Cue (Inhibitor, Preexposed, Novel, Alternative) showed a significant main effect of Cue, $F(3,75)=10.9, M S e=607.6$, $p<.001, \mathrm{n}_{\mathrm{p}}{ }^{2}=.30$. Nothing else was significant, largest $F(3,75)=1.3, M S e=184.1, p=$ .28 for the Outcome $x$ Cue interaction. Post-hoc comparisons confirmed higher rating scores to the novel compounds than to the inhibitory, $p<.01$, preexposed, $p<.01$, and alternative compounds, $p<.001$. No other difference was statistically significant. The 
analysis confirmed that participants rated the likelihood of outcome presentation to be as low during the preexposed cues as during the Pavlovian inhibitors, and lower in the presence of all these compounds than the novel stimuli (Inhibitor $=$ Alternative $=$ Preexposed< Novel); in addition ratings were unaffected by whether the $\mathrm{Cl}$ was trained with the same outcome as the transfer cue or the alternative outcome (Inhibitor = Alternative), showing that, just as in Alarcón \& Bonardi (2016) the inhibitors were not outcome-specific by this measure.

\section{[Figure 1 here]}

The results of the PIT test are presented in Figure 2, which shows that, as expected, the transfer cues $\left(T_{1}\right.$ and $\left.T_{2}\right)$ elicited more Same than Different responses when presented with the novel control stimuli $\left(T_{1} N_{1}\right.$ and $\left.T_{2} N_{2}\right)$. This outcome-specific PIT effect appeared equally substantial in the preexposed stimulus compounds $T_{1} C_{1}$ and $T_{2} C_{2}$, but was reduced with the inhibitory compounds $\left(T_{1} l_{1}\right.$ and $\left.T_{2} I_{2}\right)$. ANOVA with Outcome (Same, Different) and Compound (Preexposed, Inhibitory, Novel) as factors showed a significant main effect of Outcome, $F(1,25)=9.7, M S e=15389.1, p<.01, \eta_{p}{ }^{2}=.28$ and a significant Outcome $x$ Compound interaction, $F(2,50)=3.27, M S e=4936.2, p=.046, \eta_{p}^{2}=.12$. The effect of Compound was not significant, $F<1$. Exploration of the interaction confirmed higher Same than Different responses for the Preexposed, $F(2,50)=13.92, M S e=$ 4936.2, $p<.001$, and Novel compounds, $F(2,50)=21.52, M S e=4936.2, p<.001$, but not for the Inhibitory compounds, $F(1,50)=1.33, M S e=4936.2, p=.27$. Equivalent analysis of preCS responding revealed nothing significant, largest $F(2,50)=1.13, M S e=5327.89$, $p=.33$ for the Outcome $x$ Compound interaction. For the preexposed $\left(T_{1} C_{1}, T_{2} C_{2}\right)$, inhibitory $\left(T_{1} l_{1}, T_{2} I_{2}\right)$ and novel $\left(T_{1} N_{1}, T_{2} N_{2}\right)$ compounds respectively the mean preCS Same responses were $185.2(\mathrm{SEM}=31.5), 192.9(\mathrm{SEM}=33.1)$ and $173.8(\mathrm{SEM}=30.0)$, 
and the mean Different responses $176.5($ SEM $=28.6), 167.9(\mathrm{SEM}=30.3)$ and 191.5 $(\mathrm{SEM}=33.9)$.

[Figure 2 here]

\section{Discussion}

This experiment aimed to establish whether, in our procedure, preexposed stimuli would behave like conditioned inhibitors in summation and PIT tests. When compounded with the novel control stimuli $\mathrm{N}_{1}$ and $\mathrm{N}_{2}$, the transfer cues $T_{1}$ and $T_{2}$, elicited expectation of their respective outcomes; moreover this effect was significantly reduced when they were compounded with the inhibitors $\mathrm{I}_{1}$ and $\mathrm{I}_{2}$, and also the preexposed control stimuli $\mathrm{C}_{1}$ and $\mathrm{C}_{2}$. This indicates that preexposure of $\mathrm{C}_{1}$ and $\mathrm{C}_{2}$ in training had made them as inhibitory as 'true' Pavlovian inhibitors. Karazinov and Boakes (2004) also found that preexposed cues were more inhibitory than novel cues in a summation test, but - in contrast to our findings less so than Pavlovian inhibitors, a difference we also observed in previous work (Alarcón \& Bonardi, 2016). Karazinov and Boakes speculated that the difference between the Pavlovian and differential inhibitors stemmed from differences in how they were trained. While the Pavlovian $\mathrm{Cl}$ was trained both as a single cue and in a compound, the preexposed differential $\mathrm{Cl}$ was only trained alone. Seeing the preexposed cue in a compound for the first time at test might have produced uncertainty in the participants, making their ratings to this compound more conservative than to the other cues (the ratings to this compound were closer to the centre of a rating scale marked as "Don't know"). However, in both Alarcón \& Bonardi (2016) and the experiment reported here the Pavlovian Cls and the preexposed stimuli were presented the same number of times as single cues and compounds across the task, making it unlikely this factor was responsible. One potentially critical difference between our two studies is that Alarcón and Bonardi (2016) = which was primarily aimed to explore the effect of Pavlovian inhibition on PIT - 
excluded participants who had not learned the Pavlovian inhibitory discrimination in training. It is possible that considering only the participants that showed inhibition in the $\underline{\text { summation test might have increased the differences between the preexposed control and }}$ the inhibitor in the PIT test; however, we reanalysed the data of the present experiment using the same response criterion as Alarcón and Bonardi (2016), but still found no significant differences between these cues.

In summary, although the summation technique indicates that preexposure produces conditioned inhibition, it is unclear whether or not this is as strong as that produced by Pavlovian training. Moreover - in view of the failure of Karazinov and Boakes to manipulate the degree of differential inhibition as theory would predict - it is also worth considering alternative explanations. For example, perhaps the preexposed cue is becoming associated with the idea that 'nothing' is going to happen, and expectation of this neutral event interferes with expectation of the outcome, reducing response ratings. This could have a similar effect in the summation test as the active expectation of outcome omission produced by the Pavlovian inhibitor (cf. Alarcón \& Bonardi, 2016).

Consistent with this suggestion, although the results of the summation test suggested the preexposed cues acquired inhibitory properties, the PIT test did not. Here the selective elevation of instrumental responding produced by $T_{1}$ and $T_{2}$ - outcomespecific PIT - was eliminated only by the Cls, and by neither the preexposed or novel cues, which did not differ (cf. Alarcón \& Bonardi, 2016). These results suggest that - in contrast to the results of the summation test - the preexposed cues were not inhibitory. This discrepancy between summation and PIT tests may be due to their differential sensitivity in detecting, perhaps subtle, differences in inhibition. Moreover, our sample size may not have been large enough to detect small differences between the inhibitors and the preexposed controls in the summation test, and between the preexposed controls and the 
novel cues in the PIT test. For instance, a larger sample size might have revealed that the preexposed controls were inhibitory relative to the novel cues, but less so than the Pavlovian inhibitors i.e., inhibitors < preexposed < novel. Alternatively it may be that the nature of the inhibitory properties endowed by Pavlovian inhibition training and nonreinforced preexposure is qualitatively different, and thus manifests differently depending on how it is tested. This would suggest that simple preexposure does not result in true inhibition, summation tests are sensitive to factors other than pure Pavlovian inhibition, and the PIT test is a purer measure of this property. These alternative explanations make it necessary to continue studying the effect of conditioned inhibition on $\underline{\text { PIT. }}$

Another feature of Alarcón and Bonardi (2016)'s results was that the inhibitor for $\mathrm{O}_{1}$ reduced summation and PIT effects just as much for $T_{2}$ as for $T_{1}$, suggesting that its inhibition was not outcome-specific. We suggested that this might be because only one Clno US relationship was trained, and so in the present study we trained two inhibitors, one for each of the outcomes. However, this had no effect on the result: in the summation test there was no difference in expectation of the outcomes during the inhibitory compounds, regardless of whether the inhibitor predicted omission of the outcome predicted by the excitor with which it was paired, or the alternative outcome. In fact there is already some controversy over whether conditioned inhibitors are specific to the sensory properties of the outcomes whose omission they signal, or whether they act via a solely motivational mechanism. Initial studies suggested that conditioned inhibitors trained with a specific US, such as a shock to the left eye, would inhibit responding equally to any CS signalling shock, regardless of the eye to which it was delivered (Pearce, Montgomery, \& Dickinson, 1981; Nieto, 1984; see Lolordo \& Fairless, 1985 for a review). In contrast, more recent research, using PIT measures of inhibition, suggests a different story. Quail and 
colleagues (Quail, Laurent, \& Balleine, 2017; see also Laurent, Wong \& Balleine, 2015) used a human task to train two inhibitors, one for each of two outcomes $\left(S_{1} \rightarrow O_{1}, S_{2} \rightarrow O_{2}\right.$, $S_{1} I_{1} \rightarrow$ nothing, $S_{2} I_{2} \rightarrow$ nothing). The effects of $I_{1}$ and $I_{2}$ were evaluated in a PIT test, both when presented alone, when paired with the CSs with which they were trained $\left(S_{1} l_{1}, S_{2} I_{2}\right)-$ and with the alternative CSs $\left(S_{1} I_{2}, S_{2} I_{1}\right)$. If $I_{1}$, for example, were a specific inhibitor for $\mathrm{O}_{1}$, it should reduce the PIT effect produced by $S_{1}-$ which predicts the precise outcome whose omission $\mathrm{l}_{1}$ signalled - but not that produced by $\mathrm{S}_{2}$, which predicted the alternative outcome. This is what the authors observed.

Unfortunately there were many differences between this study that demonstrated outcome-specific inhibition and our experiments which did not. One is that we evaluated learning in each trial of the Pavlovian conditioning phase by asking participants to press a key to predict the outcome to be delivered. Because of this, participants had to choose the option "Nothing" for the conditioned inhibitors and the control cues. It is possible that this consequence, being common to both inhibitors, hindered the development of outcomespecific inhibition. Quail et al. (2017), in contrast, evaluated learning at the end of the $\underline{\text { Pavlovian conditioning phase, and participants could answer if the inhibitor was associated }}$ with the absence of a particular outcome, e.g. $\mathrm{I}_{1}$ followed by no food, or with the general absence of the outcomes, e.g., $\underline{I}_{1}$ followed by no foods or drinks, which might have encouraged a discrimination between the conditioned inhibitors. In addition, Quail et al. separated their participants based on these answers (Experiment 2), finding that the "specific learners", who identified specific inhibitor->no outcome relationships, showed high levels of outcome-specificity in the PIT test, whereas the "general learners", those who identified the inhibitors as signalling the absence of any outcome, did not show any signs of such specificity. It is possible that we might show a similar effect by separating the 
participants similarly, however, our measures of Pavlovian learning do not allow us to divide our participants into specific or general learners.

Another difference is that Quail et al. did not evaluate their inhibitors' properties against separately trained test excitors, and only used a PIT test (Rescorla, 1969). Conversely, our first experiment that demonstrated non-outcome-specific inhibition in the PIT test only trained one inhibitor, while in the present experiment we did not evaluate the alternative compounds in the PIT test. Our evidence for non-outcome-specific inhibition came only from a summation test, which Quail et al., did not include. Thus there is no real conflict of results here - but a key need to bridge the gap between these various studies in order to establish whether or not inhibition is outcome-specific in these kinds of task.

Another point worth mentioning is the use of a brief instrumental retraining before the PIT test, which purpose was to serve as a reminder of the instrumental associations learned at the beginning of the task (see Alarcón \& Delamater 2019 for the same procedure in rodent research). It might be argued that this is similar to an "overtraining" procedure, resulting in habitual responding rather than goal-directed behaviour, which is less dependent on the outcome representation. However, we do not consider this training to be sufficient to produce habits. There is one example in which habits have been achieved by overtraining instrumental responses in humans but it required several separate sessions of instrumental conditioning (Tricomi, Balleine \& O'Doherty, 2009), and $\underline{\text { recently a series of failed attempts to reproduce those findings have been published (de }}$ Wit et al., 2018). Related to overtraining, Garofalo and Robbins (2017) provided evidence that extended training in humans enhances the outcome-specific PIT effect and it would interesting to assess if the ability of the conditioned inhibitors to reduce selective PIT remains after instrumental overtraining. 
A final consideration is that, although it was designed to be similar to the tasks used in animal research, we did not obtain a direct measure of Pavlovian conditioning but rather asked participants about explicit expectations of the outcomes, as in contingency learning tasks (e.g., Shanks, 2007). Some researchers have argued that the processes involved in this type of task depend on the generation of propositions about the relationships between the events, rather than the traditional associative view, and there have been recent efforts to explain outcome-specific PIT with a propositional account (e.g., Hogarth et al., 2014; Seabrooke, Hogarth, \& Mitchell, 2016). However, the outcomespecific PIT effect is consistently found in both animal and human studies, suggesting that the measure of Pavlovian conditioning might not be critical. For instance, the inhibition of PIT results found by Quail et al. (2017) were remarkably similar to previous results found in rodents by the same group of researchers (Laurent et al., 2015). Nevertheless, adding direct measures of Pavlovian conditioning might provide further information about the underlying processes in this type of task.

In summary, we have demonstrated that simple preeexposure can make a stimulus behave like a conditioned inhibitor in a summation test, relative to a novel control; however, this was not evident in a PIT test of inhibition. Of several possible interpretations, one possibility is that summation tests are sensitive to effects other than Pavlovian inhibition, and that the PIT test is a better measure of a stimulus' inhibitory properties. We also failed to produce evidence of outcome-specific inhibition in a summation test, despite training two inhibitors, one for each outcome. Although this ostensibly contradicts findings from other studies (e.g. Quail et al., 2017), a more likely explanation is that this discrepancy arises from procedural differences. More generally, we believe that these findings expand our understanding of the mechanisms underlying PIT, and that this task 
might be helpful to study the effect of conditioned inhibition in maladaptive behaviour, such as drug-seeking behaviours and overeating.

\section{Acknowledgements}

The elaboration of this manuscript was supported by a postdoctoral grant awarded by Conicyt (Fondecyt \# 3170166) to Dr. Daniel Alarcón. 


\section{References}

Alarcón, D., \& Bonardi, C. (2016). The effect of conditioned inhibition on the specific

Pavlovian-instrumental transfer effect. Journal of Experimental Psychology: Animal

Learning and Cognition, 42, 82-94. doi: 10.1037//xan0000087

Alarcón, D. E., Bonardi, C., \& Delamater, A. R. (2018). Associative mechanisms involved in specific Pavlovian-to-instrumental transfer in human learning tasks.

https://doi.org/10.1080/17470218.2017.1342671

Alarcón, D. E., \& Delamater, A. R. (2019). Outcome-specific Pavlovian-to-instrumental transfer (PIT) with alcohol cues and its extinction. Alcohol, 76, 131-146.

Cartoni, E., Balleine, B., \& Baldassarre, G. (2016). Appetitive Pavlovian-instrumental transfer: A review. Neuroscience \& Biobehavioral Reviews, 71, 829-848. doi:10.1016/j.neubiorev.2016.09.020

de Wit, S., Kindt, M., Knot, S. L., Verhoeven, A. A., Robbins, T. W., Gasull-Camos, J., ... \& Gillan, C. M. (2018). Shifting the balance between goals and habits: Five failures in experimental habit induction. Journal of Experimental Psychology: General, 147(7), 1043.

\section{Delamater, A. R., Sosa, W., \& LoLordo, V. M. (2003). Outcome-specific conditioned} inhibition in Pavlovian backward conditioning. Learning \& Behavior, 31, 393-402. http://dx.doi.org/10.3758/BF03196000

Garofalo, S., \& Robbins, T. W. (2017). Triggering avoidance: Dissociable influences of aversive Pavlovian conditioned stimuli on human instrumental behavior. Frontiers in behavioral neuroscience, $11,63$.

Hogarth, L., Retzler, C., Munafo, M. R., Tran, D. M., Troisi, J. R., Rose, A. K., . . Field, M. 


\section{(2014). Extinction of cueevoked drug-seeking relies on degrading hierarchical}

instrumental expectancies. Behaviour Research and Therapy, 59, 61-70

\section{Holmes, N. M., Marchand, A. R., \& Coutureau, E. (2010). Pavlovian to instrumental}

transfer: A neurobehavioural perspective. Neuroscience \& Biobehavioral Reviews, 34, 1277-1295. doi:10.1016/j.neubiorev.2010.03.007

Karazinov, D. M., \& Boakes, R. A. (2006). Learning about cues that prevent an outcome:

Conditioned inhibition and differential inhibition in human predictive learning, 04(2), 153-178. https://doi.org/10.1080/02724990344000033

Laurent, V., Wong, F. L., \& Balleine, B. W. (2015). ס-Opioid receptors in the accumbens shell mediate the influence of both excitatory and inhibitory predictions on choice. British Journal of Pharmacology, 172(2), 562-570. https://doi.org/10.1111/bph.12731

\section{LoLordo, V. M. (1967). Similarity of conditioned fear responses based upon different} aversive events. Journal of Comparative and Physiological Psychology, 64(1), 154158.

LoLordo, V. M., \& Fairless, J. L. (1985). Pavlovian conditioned inhibition: The literature since 1969. In Information processing in animals: Conditioned inhibition, ed. R.R. Miller, N. E. Spear, pp. 1-49. Hillsdale, N. J.: Earlbaum.

Miller, R. R., Hallam, S. C., Hong, J. Y., \& Dufore, D. S. (1991). Associative structure of differential inhibition: implications for models of conditioned inhibition. Journal of Experimental Psychology. Animal Behavior Processes, 17(2), 141-150. https://doi.org/10.1037/0097-7403.17.2.141

Nieto, J. (1984). Transfer of conditioned inhibition across different aversive reinforcers in the rat. Learning and Motivation, 15(1), 37-57. https://doi.org/10.1016/0023- 


\section{0(84)90015-8}

Pearce, J. M., Montgomery, A., \& Dickinson, A. (1981). Contralateral transfer of inhibitory and excitatory eyelid conditioning in the rabbit. Quarterly Journal of Experimental Psychology: Comparative \& Physiological Psychology, 33(1), 45-61.

https://doi.org/10.1080/14640748108400828

Peirce, J. W. (2007). PsychoPy-Psychophysics software in Python. Journal of Neuroscience Methods, 162(1-2), 8-13. https://doi.org/10.1016/j.jneumeth.2006.11.017

Quail, S. L., Laurent, V., \& Balleine, B. W. (2017). Inhibitory pavlovian-instrumental transfer in humans. Journal of Experimental Psychology: Animal Learning and Cognition, 43(4), 315-324. https://doi.org/10.1037/xan0000148

Rescorla, R. A. (1969). Pavlovian conditioned inhibition. Psychological Bulletin, 72, 77-94. http://dx.doi.org/10.1037/h0027760

Rescorla, R. A., \& Solomon, R. L. (1967). Two-process learning theory: Relationships between Pavlovian conditioning and instrumental learning. Psychological review, 74(3), 151.

Seabrooke, T., Hogarth, L., \& Mitchell, C. J. (2016). The propositional basis of cuecontrolled reward seeking. The Quarterly Journal of Experimental Psychology, 69, 2452-2470.doi:10.1080/17470218.2015.1115885

Shanks, D. R. (2007). Associationism and cognition: Human contingency learning at 25. The Quarterly Journal of Experimental Psychology, 60(3), 291-309.

Trapold, M. A., \& Overmier, J. B. (1972). The second learning process in instrumental learning. In A. H. Black \& W. F. Prokasy (Eds.), Classical conditioning II: Current 


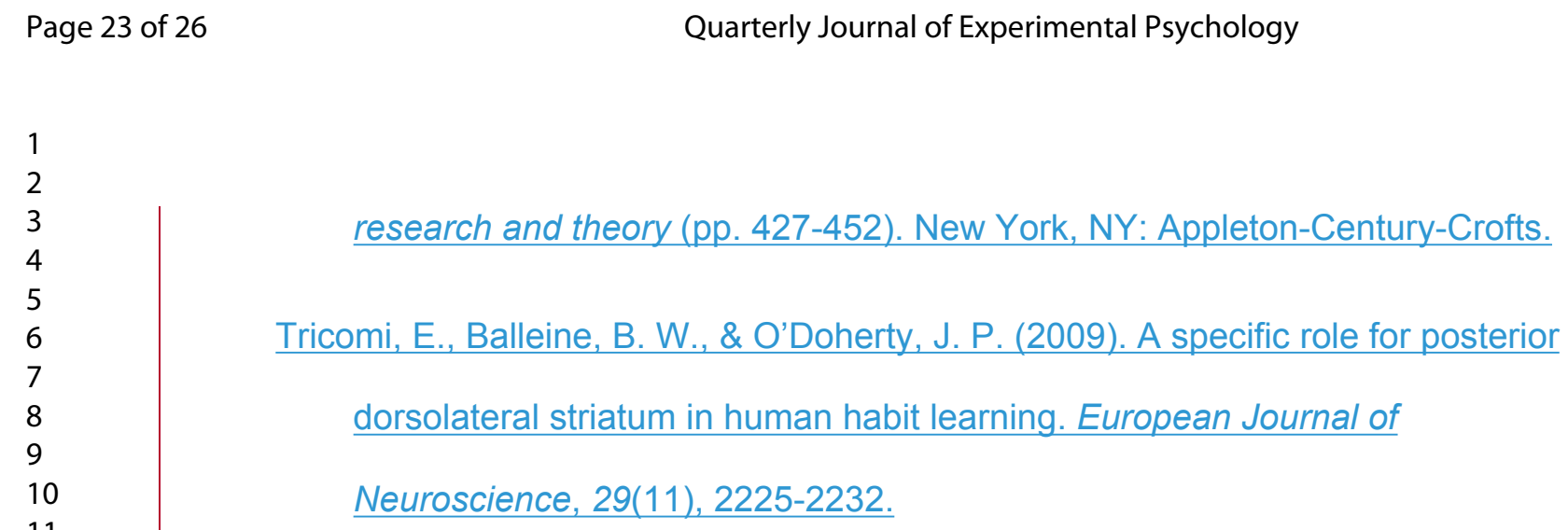

research and theory (pp. 427-452). New York, NY: Appleton-Century-Crofts.

$\underline{\text { Tricomi, E., Balleine, B. W., \& O’Doherty, J. P. (2009). A specific role for posterior }}$

dorsolateral striatum in human habit learning. European Journal of

Neuroscience, 29(11), 2225-2232. 
Table 1. Experimental design.

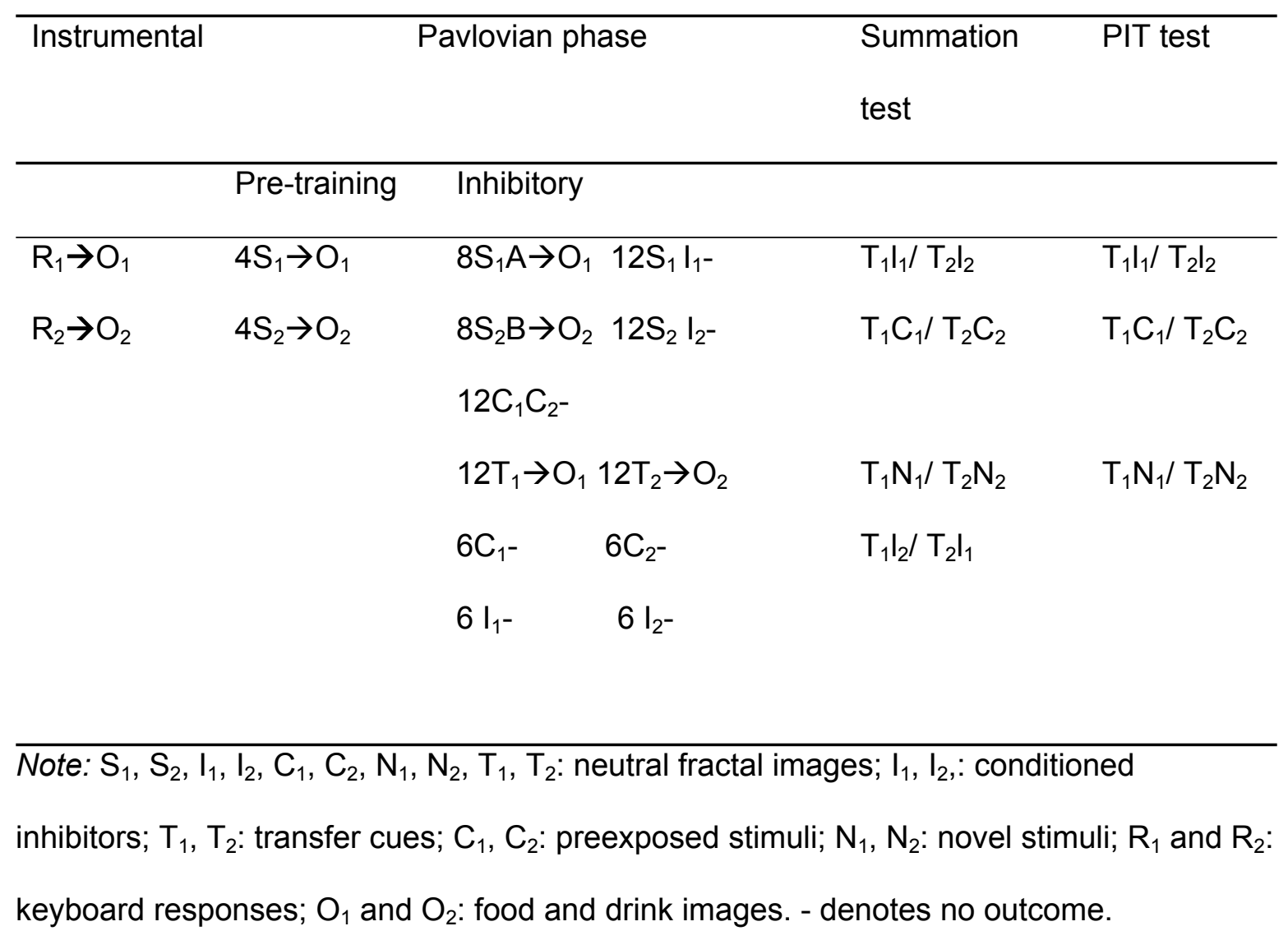




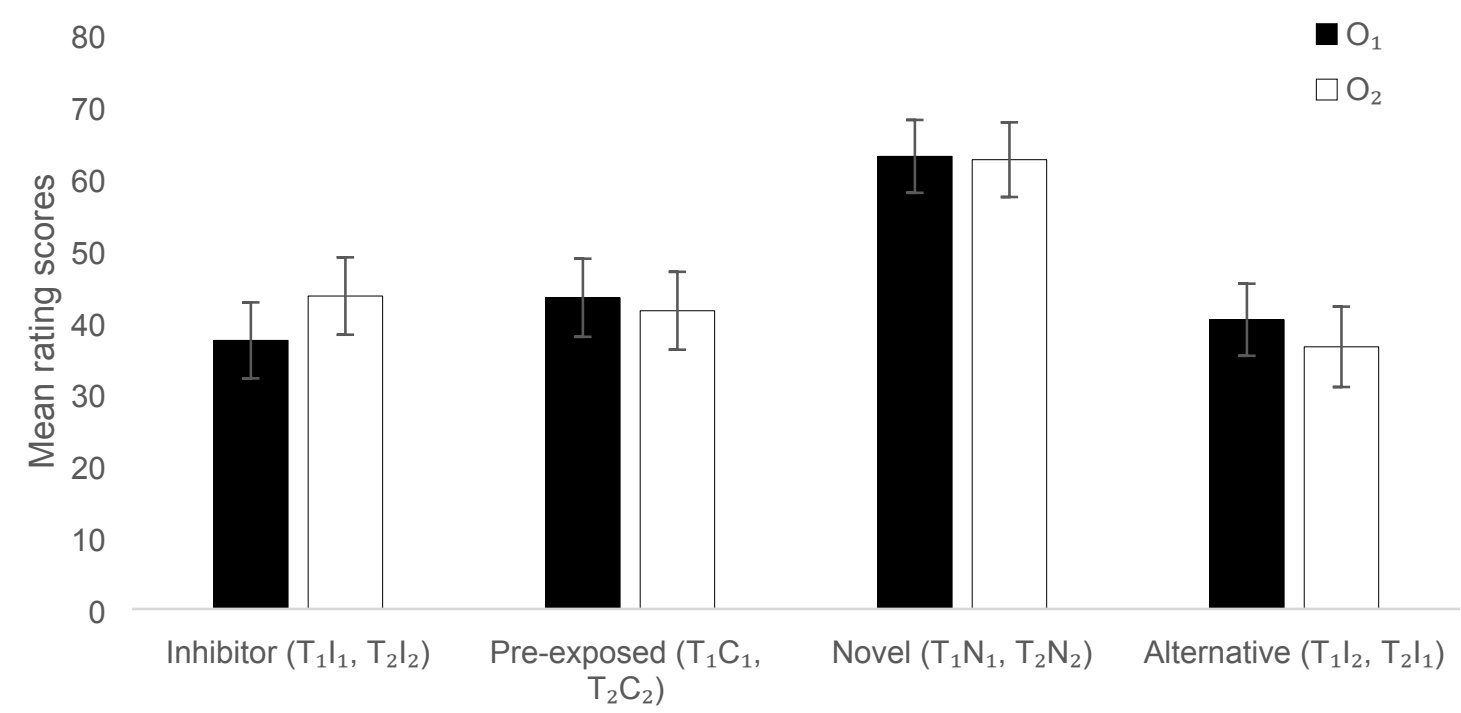

Figure 1. Mean rating scores (participants' expectancies) \pm SEM to the questions about $O_{1}$ and $\mathrm{O}_{2}$ for the transfer cues in compound with the inhibitors $\left(T_{1} l_{1}, T_{2} l_{2}\right)$ the preexposed control cues $\left(T_{1} C_{1}, T_{2} C_{2}\right)$, the novel control cues $\left(T_{1} N_{1}, T_{2} N_{2}\right)$ and the alternative inhibitors $\left(T_{1} l_{2}, T_{2} l_{1}\right)$ in the summation test. 


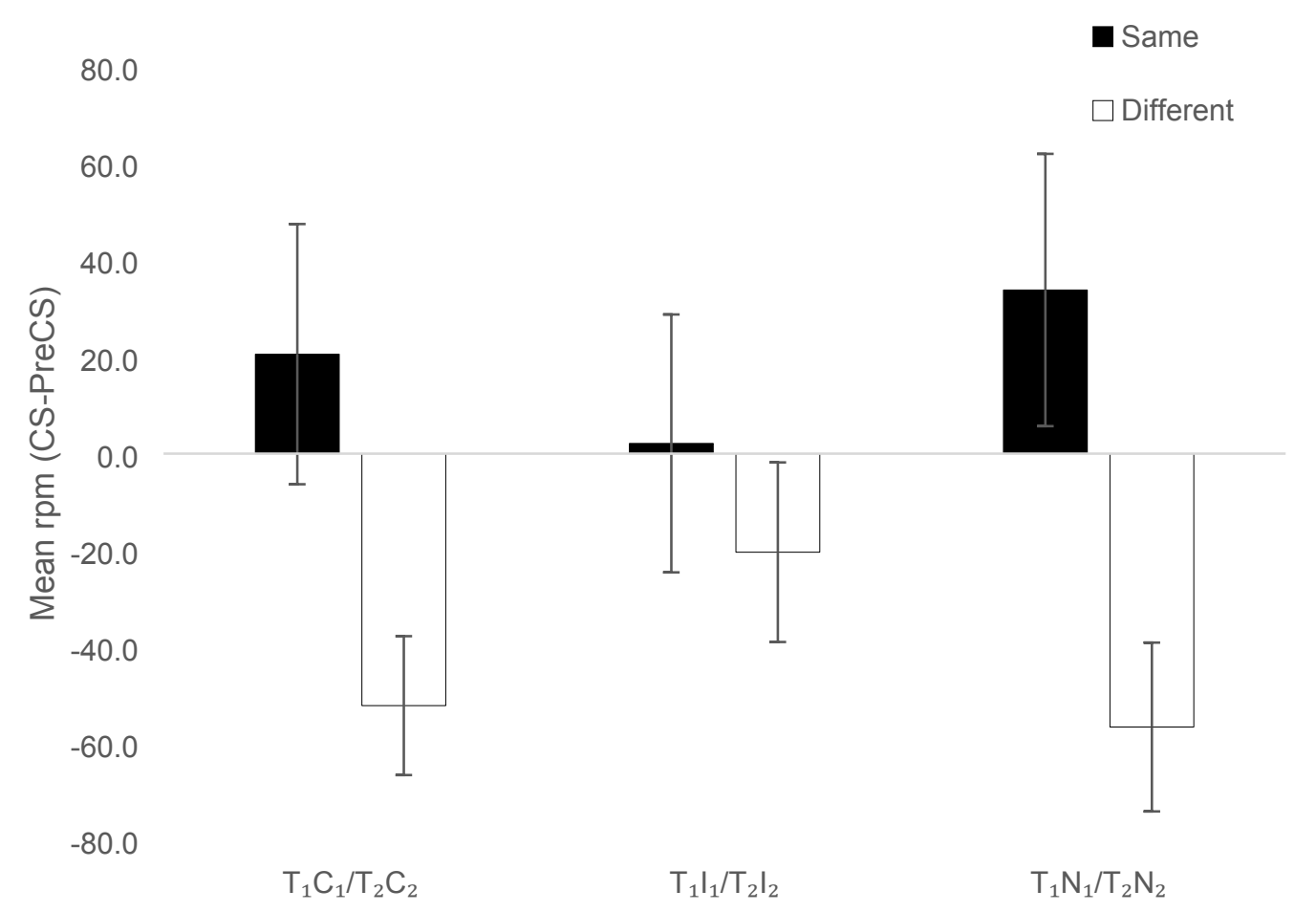

Figure 2. Same and Different responding to the transfer cues in compound with the preexposed control stimuli $\left(T_{1} C_{1} / T_{2} C_{2}\right)$, the inhibitors $\left(T_{1} l_{1} / T_{2} l_{2}\right)$, and novel control cues $\left(T_{1} N_{1} / T_{2} N_{2}\right)$ in the PIT test. 